\title{
JOÃO CURSINO DA GAMA: A TRAJETÓRIA DE UMA LIDERANÇA OPERÁRIA SOCIALISTA NO AMAZONAS (1902-1935)
}

\section{Luciano Everton Costa Teles*}

\section{RESUMO:}

O presente texto procura sublinhar a trajetória de João Cursino da Gama, um importante líder operário socialista no Amazonas. Gama deixou Pernambuco e se deslocou para o Amazonas por volta do início do século XX. Em Manaus, passou a agir na organização dos trabalhadores, ajudando a fundar associações, partido operário e jornais, nos quais escreveu. No final da década de 1920 foi eleito para o Conselho Municipal, onde inseriu a pauta operária nas discussões. Entrou pela década de 1930 como vereador eleito em mais de dois mandatos. O objetivo do artigo consiste em, por intermédio da trajetória de Gama e a partir de suas "expressões individuais", realçar a luta operária socialista no Amazonas e a "invenção do trabalhismo" local, apontando a necessidade de pesquisas históricas que foquem as continuidades existentes entre esses dois períodos.

Palavras-chave: João Cursino da Gama; Socialismo; Amazonas.

\begin{abstract}
:
The present text seeks to underline the trajectory of João Cursino da Gama, an important socialist labor leader in Amazonas. Gama left Pernambuco and moved to the Amazon around the beginning of the 20th century. In Manaus he began to act in the organization of the workers, helping to found associations, workers' parties and newspapers, in which he wrote. In the late 1920s he was elected to the Municipal Council, where he inserted the workers' agenda in the discussions. He entered the 1930s as an elected councilor in more than two terms. The objective of the article is to highlight, through Gama's trajectory and from his "individual expressions", the socialist workers' struggle in Amazonas and the local "invention of labor", pointing out the need for historical research that focuses on the existing continuities Between these two periods.
\end{abstract}

Keywords: João Cursino da Gama; Socialism; Amazonas.

A historiografia regional durante algumas décadas jogou luzes sobre as transformações econômicas e sociais que atingiram o Amazonas, particularmente a cidade de Manaus, no contexto da exportação da borracha. Tanto a cadeia de comercialização do látex quanto à modernização pela qual a capital amazonense passou foram colocadas no centro da cena histórica. Como decorrente quase que exclusivamente das questões econômicas, o devir

\footnotetext{
* Doutorando em História pela Universidade Federal do Rio Grande do Sul. Mestre em História Social pela Universidade Federal do Amazonas. Professor Assistente 2 da Universidade do Estado do Amazonas/CEST. Email: lucianoeverton777@ hotmail.com
} 
histórico acabava por inserir a região no mercado mundial e, consequentemente, nos trilhos do "progresso" e da "civilização", cuja referência maior era a Paris de Haussmann. A elite extrativista e comercial foi sublinhada para demonstrar esse processo. As contradições internas e outros grupos sociais acabaram sendo varridos para "debaixo do tapete" da História.

Certamente que o quadro atual da historiografia superou esse esquema explicativo. Obras como "A ilusão do fausto", "A cidade sobre os ombros", "Quando viver ameaça a ordem urbana"3 e dissertações de mestrado como "O patronato amazonense e o mundo do trabalho", "Infância e trabalho"5, "Trabalho e emancipação", "Vozes operárias", dentre outros, apontaram os limites de uma escrita da História preocupada estritamente com o fenômeno urbano e/ou com a elite local e recuperaram outros sujeitos históricos e dimensões sociais importantes que foram esquecidos. Nessa esteira, vários segmentos sociais como mulheres, crianças, imigrantes e trabalhadores foram gradativamente sendo resgatados, não como coadjuvantes, mas como protagonistas no processo histórico. Sobre o universo operário, Luís Balkar Sá Peixoto Pinheiro destacou que:

Diante de um contexto historiográfico ancorado em posturas glorificadoras com evidentes conotações elitistas, um olhar sobre o universo operário no Amazonas da virada do século XIX para o século XX, não só se mostra relevante, como urgente. Nesse sentido, trata-se de alargar o campo de abordagem de uma Nova História Social que vem lentamente se impondo no Amazonas desde as duas últimas décadas, com a realização de importantes trabalhos (dissertações e teses) sobre o tema do trabalho e do trabalhador urbano no Norte do país ${ }^{8}$.

Alguns desses trabalhos foram mencionados anteriormente. Porém, não se pode deixar de colocar em relevo as significativas contribuições de Luís Balkar Sá Peixoto Pinheiro e Maria Luiza Ugarte Pinheiro no sentido de iluminar e refletir sobre temas como mundos do

\footnotetext{
${ }^{1}$ DIAS, Ednéa Mascarenhas. A ilusão do fausto: Manaus, 1890-1920. Manaus: Editora Valer, 1999.

2 PINHEIRO, Maria Luiza Ugarte. A cidade sobre os ombros: trabalho e conflito no porto de Manaus (18991925). Manaus: Edua, 1999.

${ }^{3}$ COSTA, Francisca Deusa Sena da. Quando viver ameaça a ordem urbana: cotidiano de trabalhadores em Manaus, 1915-1925. Dissertação (mestrado em História), PPGH/PUC-SP, São Paulo, 2000.

4 AVELINO, Alexandre Nogueira. O patronato amazonense e o mundo do trabalho: a Revista da Associação Comercial e as representações acerca do trabalho no Amazonas (1908-1919). Dissertação (mestrado em História), PPGH/UFAM, Manaus, 2008.

${ }^{5}$ PESSOA, Alba Barbosa. Infância e trabalho: dimensões do trabalho infantil na cidade de Manaus. Dissertação (mestrado em História), PPGH/UFAM, Manaus, 2010.

${ }^{6}$ CAMPOS, Luciane Maria Dantas de. Trabalho e emancipação: um olhar sobre as mulheres de Manaus (18901930). Dissertação (mestrado em História), PPGH/UFAM, Manaus, 2010.

${ }^{7}$ BARROS, Cláudia Amélia Mota Moreira. Vozes Operárias: os tipógrafos e a construção da identidade operária amazonense (1891-1914). Dissertação (mestrado em História), PPGH/UFAM, Manaus, 2015.

${ }^{8}$ PINHEIRO, Luís Balkar Sá Peixoto. Imprensa e mundos do trabalho na Belle Époque manaura. In: XXII SIMPÓSIO NACIONAL DE HISTÓRIA, 22, 2003, João Pessoa. Anais do XXII Simpósio Nacional de História: História, acontecimento e narrativa. João Pessoa: ANPUH, 2003, p. 1.
} 
trabalho, associações, lideranças, greves, entre outros. Não deixaram também de se preocupar com as fontes históricas produzidas pelos e para os trabalhadores, como, por exemplo, os jornais operários, buscando organizá-los e disponibilizá-los no Laboratório de História da Imprensa no Amazonas (LHIA) ou em livros de transcrições e fac-símiles ${ }^{9}$. Para os autores, a imprensa operária é fundamental para incorporar "os sujeitos sociais que ficaram à margem do veio central de uma historiografia que, afeita aos grupos dominantes, continua a exercer sua hegemonia no Norte do país" ${ }^{\prime 10}$.

Com efeito, os trabalhadores, especificamente as suas lideranças, e os jornais que produziram, e que foram preservados nos acervos da região amazônica, colocam-se como fontes importantes que permitem recuperar não apenas suas trajetórias individuais (e de grupos), mas também suas lutas e seus projetos políticos e sociais no interior de uma sociedade desigual, excludente e conflituosa como era a Manaus da "Belle Époque".

Este artigo tem como foco analisar a trajetória de uma importante liderança operária socialista no Amazonas, João Cursino da Gama. Através de seus passos buscou-se realçar a luta operária socialista na região e a "invenção do trabalhismo" local, apontando a necessidade de pesquisas históricas que foquem nas continuidades existentes entre esses dois períodos.

\section{João Cursino da Gama: de Pernambuco para o Amazonas}

João Cursino da Gama era Pernambucano ${ }^{11}$. Filho de Genuína Dias Vieira da Gama e Alfredo Lopes da Gama ${ }^{12}$. Seu pai exercia a profissão de professor em Recife. Gama se deslocou para Manaus nos anos iniciais do século XX. Talvez por volta de 1902, ano em que apareceu nos jornais da região. Não se sabe exatamente os motivos que provocaram essa movimentação em direção à capital do Amazonas. Provavelmente por conta das condições difíceis existentes no Nordeste nesse período e/ou da possibilidade de uma nova vida, em virtude das propagandas oficiais que eram feitas sobre o "boom" da borracha e as supostas oportunidades de emprego ou até mesmo de "notícias" de enriquecimento que se ventilavam sobre os indivíduos que vinham para o Amazonas.

Certamente que, em se tratando de fluxo migratório, sobretudo nordestino, não se pode reduzí-lo às questões econômico-sociais e/ou à seca, condições objetivas externas que acabam

\footnotetext{
${ }^{9}$ Ambos são coordenadores do LHIA. O livro publicado foi PINHEIRO, Luís Balkar Sá Peixoto, PINHEIRO, Maria Luiza Ugarte (orgs.). Imprensa Operária no Amazonas (Transcrições e fac-símiles). Manaus: EDUA, 2004.

${ }^{10}$ Idem, p. 10.

${ }^{11}$ JORNAL DO COMMERCIO. Manaus, ano VI, 2/11/1909.

${ }^{12}$ JORNAL DO COMMERCIO. Manaus, ano VIII, n. 2694, 21/10/1911.
}

CANOA DO TEMPO - Revista do Prog. Pós-Graduação em História, Manaus, V. 9 - no1, dez 2017. 
retirando a condição de sujeito daquele que optou por deslocar-se. Deve-se considerar também a escolha individual/coletiva dos que realizaram esse deslocamento. Além disso, cabe atentar para os elementos de atração que influenciaram a escolha do destino (Estado/Cidade). Conforme Deusamir Pereira, para o Amazonas ocorreram dois elementos de atração: o primeiro foi a indução através do aliciamento de braços e o segundo através da ideia do "El Dorado" $"$.

Quanto ao primeiro, é notório que a escassez de braços era uma preocupação das autoridades governamentais na Amazônia, especialmente na extração do látex para o mercado mundial. Roberto Santos externou em sua obra esse ponto ${ }^{14}$. Como alternativa se criou um processo de aliciamento de força de trabalho em outras regiões, como o Nordeste brasileiro. Lá se montou uma estrutura de recrutamento de mão de obra para os seringais através de uma política de governo e propaganda oficial. Esta realçava as supostas oportunidades de melhoraria de vida no contexto da exportação da borracha.

Isso nos leva ao segundo elemento, ou seja, a ideia do "El Dorado", do enriquecimento fácil, que seduziu e motivou muitos nordestinos a saírem de sua terra natal em direção à floresta tropical. Sobre essa migração interna Hermenegildo de Campos, médico sanitarista do início do século XX em Manaus, realizou uma estatística, no ano de 1907, e revelou que a metade dos 50.000 brasileiros, que em associação com outros 10.000 estrangeiros formavam a população de Manaus, era constituída por migrantes vindos de outros Estados, particularmente do Nordeste do país ${ }^{15}$.

Dessa forma, junto com outros conterrâneos, João Cursino da Gama passou a residir no Amazonas. Não foi para os seringais, destino da grande maioria, mas fixou-se na capital no bojo do processo de urbanização e modernização do início do século XX. Tornou-se sócio do Centro Pernambucano em Manaus, criado por homens de sua terra natal. Aqui conheceu Nicodemos Pacheco, seu conterrâneo e futuro camarada de luta ${ }^{16}$.

Adentrou no mercado de trabalho como funcionário público do Estado, lotado na Diretoria de Obras Públicas, exercendo o cargo de guarda dos materiais do Estado ${ }^{17}$. Fez parte

\footnotetext{
${ }^{13}$ PEREIRA, Deusamir. Amazônia (in)sustentável: Zona Franca de Manaus - estudo e análise. Manaus: Valer, 2006, p. 81.

${ }^{14}$ SANTOS, Roberto. História Econômica da Amazônia (1800-1920). São Paulo: editora T. A. Queiroz, 1980.

${ }^{15}$ CAMPOS, Hermenegildo Lopes de. Climatologia Médica do Estado do Amazonas. $2^{\mathrm{a}}$ ed. Manaus: Associação Comercial do Amazonas, 1988, p. 100-103.

${ }^{16}$ JORNAL DO COMMERCIO. Manaus, ano VI, 2/11/1909.

${ }^{17}$ JORNAL DO COMMERCIO. Manaus, ano XVI, n. 2352, 24/2/1919.
} 
da Diretoria do Centro Esportivo Derby-Club, como Secretário ${ }^{18}$. Também marcou presença no Hipódromo Amazonense como Juiz de Partida.

No Hipódromo, Gama atuava juntamente com Pacheco, que era Juiz de Pesagem, e com Nicolau Pimentel, Juiz de Encilhamento. Este último provavelmente o conheceu nesse espaço. Os três se tornaram importantes lideranças operárias socialistas locais, porém com conexões nacionais e internacionais. Pacheco era agente de polícia e Pimentel era gráfico ${ }^{19}$.

Ao longo dos anos da década de 1910, além de trabalharem e participarem como Juízes no Hipódromo, passaram a organizar os trabalhadores amazonenses. A tabela abaixo traz uma pequena ideia do quantitativo de nordestinos que estavam inseridos no mercado de trabalho manauara:

TABELA 1

\begin{tabular}{|c|c|}
\hline Naturalidade & Números \\
\hline Amazonas & 362 \\
\hline Ceará & 116 \\
\hline Pará & 95 \\
\hline Paraíba & 66 \\
\hline Maranhão & 66 \\
\hline Rio Grande do Norte & 50 \\
\hline Pernambuco & 38 \\
\hline Piauí & 15 \\
\hline Bahia & 13 \\
\hline Sergipe & 12 \\
\hline Acre & 12 \\
\hline Alagoas & 11 \\
\hline Rio de Janeiro & 5 \\
\hline Minas Gerais & 2 \\
\hline Rio Grande do Sul & 2 \\
\hline Espírito Santo & 1 \\
\hline TOTAL & 866 \\
\hline
\end{tabular}

Fonte: Livro de registros da Associação União Operária Amazonense. Acervo CEMEJ.

In: PINHEIRO, Luís Balkar Sá Peixoto Pinheiro. Imigração, trabalho e imprensa em Manaus, 1890-1928. Revista Litteris, n. 14, p. 15, set./2014.

Ela é também reveladora da composição heterogênea dos trabalhadores locais, pelo menos da parcela organizada, o que deve ser visto como um forte indício até mesmo para o conjunto do operariado. Nesse quadro mais geral, a quantidade de nordestinos chama atenção,

\footnotetext{
${ }^{18}$ JORNAL DO COMMERCIO. Manaus, ano VI, n. 2051, 14/12/1909.

19 JORNAL DO COMMERCIO. Manaus, ano X, n. 3308, 13/7/1913.
} 
algo em torno de $44 \%$ do total e, no interior desses 44\%, $10 \%$ de pernambucanos, número nada desprezível. Entre eles se encontra João Cursino da Gama.

O Centro Pernambucano em Manaus, mencionado anteriormente, tornou-se fundamental para aqueles que chegavam em Manaus e necessitavam de algum apoio. Gama foi incorporado pelo C.P., participando dele ativamente. Deve-se registrar que outros Centros (cearenses, maranhenses...) também existiam e tinham uma atuação forte localmente. Os nordestinos, nesse momento, em especial os que permaneceram na cidade de Manaus, como Gama, não somente viram as transformações políticas e econômicas pelas quais a capital do Amazonas passou, em função da implantação do regime republicano e da exportação da borracha, como também se inseriram no mercado de trabalho dinamizado e ampliado nesse contexto, vivenciando as contradições existentes entre capital/trabalho. O personagem aqui destacado estava presente nesse processo e para compreender a sua trajetória se faz mister contextualizar essas transformações.

\section{A implantação da República e a emergência do socialismo na região amazônica}

No Brasil, as duas décadas finais do século XIX foram marcadas por profundas transformações políticas, sociais e econômicas que se materializaram na diluição das relações sociais baseadas na escravidão e no desgaste da ordem monárquica vigente. Esse processo culminou com a implantação da República em 15 de novembro de 1889. Consoante Gomes, a mudança da ordem político-institucional foi, sobretudo, fruto de uma crise política:

O golpe vitorioso de Deodoro concluía, contudo, um processo que se iniciara décadas atrás, envolvendo questões cruciais como a abolição do trabalho escravo e a participação política dos militares, e que se materializara numa campanha com significativo grau de mobilização e organização, como o demonstra o Partido Republicano. Os interesses e a composição dos segmentos que se reuniram em nome da República são reconhecidamente diversos e complexos. A proclamação, se não é um momento de política revolucionária, é ao menos um momento de crise política que guarda uma característica fundamental dos episódios que inauguram novas experiências históricas: a instabilidade ${ }^{20}$.

Ainda segundo a autora, com a Proclamação da República os esforços dos grupos envolvidos se canalizaram para a definição de seu formato político e social. Os trabalhadores, na perspectiva de serem incluídos nesse movimento, elaboraram e tornaram público a sua proposta de intervenção e participação política, numa clara tentativa de contribuir junto ao processo de formação da Primeira República Brasileira. Essa posição se explica pelo sentido

\footnotetext{
${ }^{20}$ GOMES, Ângela de Castro. A invenção do Trabalhismo. São Paulo: Vértice, 1988, p. 19.
} 
que eles atribuíram ao novo regime, cuja implantação foi vista como a abertura de novos horizontes, sobretudo quanto à expectativa de reconhecimento social e participação política.

No Amazonas, essa perspectiva quanto às potencialidades de reconhecimento e participação política no novo regime não esteve ausente, como é possível observar:

Esta data, na ampulheta do tempo é inapagável e, na senda da política moralisada ella é, então - sublime e toda republicana.

É d'entre as lettras acima fluctuantes que, veio de juntarem-se dois acontecimentos na historia revolucionaria: a proclamação da República no Brazil e o apparecimento do Guttemberg na Imprensa do Amazonas.

O dia de hoje, devéras, não passará dessapercebido para os incansáveis populares de 1889 , aquelles que, prasenteiros o abrilhantavam de palmas e de risos pomposamente festivaes.

A redacção d'este periódico, vivamente de jubilo, commemora e assignala a proeminente data do $2^{\circ}$ anniversario da Republica brazileira ${ }^{21}$.

Não obstante, a desilusão quanto a essa possibilidade foi gerada a partir do momento em que o novo sistema político se mostrou incapaz de atender aos anseios dos operários ${ }^{22}$. A passagem da "esperança" para o "desencanto" ocorreu a partir do rumo que se traçou para a República. Nesse sentido, em linhas gerais, dois grandes projetos de República (com propostas crescentemente polarizadas) se colocaram em disputa entre os anos de 1892 a 1904. De um lado, os partidários de um governo forte, centralizador, intervencionista, cuja tarefa era promover o "progresso" 23 do país. Era uma proposta nitidamente positivista em sua inspiração básica, combinando as ideias de um Estado forte e democrático, já que voltado para o desenvolvimento econômico e para o "progressivismo social”. Do outro lado, situava-se a proposta elaborada pelo republicanismo civil e liberal de núcleo conhecido como o dos republicanos históricos paulistas. Tratava-se de construir uma República Liberal Excludente, federalista, francamente agrarista e ortodoxa em termos de política financeira ${ }^{24}$.

Predominou a segunda proposta. Restou aos trabalhadores lutar por espaço político e justiça social. Portanto, cabe sublinhar que a desigualdade, a exclusão social e a ausência de canais de participação política foram elementos importantes que deixaram o terreno fértil para

\footnotetext{
${ }^{21}$ GUTENBERG. Manaus, ano I, n. 1, 15/11/1891.

${ }^{22}$ BATALHA, Cláudio. Formação da Classe Operária e Projetos de Identidade Coletiva. IN: FERREIRA, Jorge, DELGADO, Lucilia de Almeida Neves (org.). O Brasil Republicano Vol 1. Rio de Janeiro: Civilização Brasileira, 2003, p. 173.

${ }^{23}$ Progresso entendido, segundo Gomes, como o reverso do atraso colonial, ou seja, da herança do domínio português, que permanecia viva numa economia exclusivamente agrária e numa sociedade de privilégios estatuídos. Por isso, o progresso comportava a atenção para as atividades da indústria e do comércio nacional (e não português) e permitia vislumbrar uma sociedade mais permeável à incorporação ordenada do trabalhador assalariado, enfim, uma sociedade mais aberta ao povo. GOMES, Ângela de Castro. A invenção do Trabalhismo... Op. Cit., p. 39.

${ }^{24}$ Idem.
} 
a emergência de ideias de críticas sociais, sejam socialistas, anarquistas e/ou comunistas. O foco aqui é o socialismo.

Um dos primeiros grupos composto por lideranças socialistas se agregou em torno dos jornais Gutenberg e Operário. O primeiro entrou em cena em 15 de novembro de 1891. Nasceu ligado à categoria dos gráficos, especialmente os tipógrafos, como periódico noticioso e literário. Já no número 19 apareceu como órgão do Partido Operário. Foi alvo de violenta repressão por força das posições políticas assumidas que caminhavam na contramão da ordem econômica, política e social vigentes e, dessa forma, foi impedido de continuar circulando. O segundo passou a existir no ano de 1892. Era a continuação do primeiro com outro nome e formato, ou seja, o mesmo grupo que estava por trás do Gutenberg agora havia lançado o Operário. Mas quem era esse grupo?

Observando esses dois jornais identificam-se alguns personagens que são importantes por difundirem as ideias socialistas no Amazonas. A grande maioria deles atuava na produção/colaboração do jornal e no partido operário. São eles: Raymundo Pinto de Vasconcelos (redator e $1^{\circ}$ Secretário do partido), Izidoro Vieira (redator e $2^{\circ}$ Secretário), Francisco Alves Medeiros, Vicente L. de Paula Galvão e Antônio Leão (todos mencionados como redatores e membros do Conselho de Diretores do partido), Marcellino da Exaltação Fernandes (redator e orador), Joaquim Carvalho (Presidente), João Diniz Gonçalves Pinto (Vice-Presidente), José Gonçalves Dias (Tesoureiro), J. A. de Figueiredo Castro, Gervásio Jorge dos Reis e Joaquim Pinto dos Santos (Membros do Conselho de Diretores) ${ }^{25}$.

Alguns desses indivíduos eram comerciantes e donos de oficinas, como João Diniz de Carvalho Pinto e José Gonçalves Dias. Outros eram empregados no comércio, como Antônio Leão e Izidoro Vieira, e gráficos, como Vicente L. de Paula Galvão ${ }^{26}$. O socialismo que eles defendiam e difundiam tinha como referência a II Internacional e, especialmente, a socialdemocracia europeia. Possuía como característica, portanto, o reformismo e o policlassismo, o que explica, por exemplo, a presença de comerciantes e empresários em torno dos jornais e do partido operário, como se pode notar acima.

Essa característica pode ser vista em outras regiões do país. Maciel apontou que os grupos socialistas de Maceió/AL também tinham atitude policlassista e reformista ${ }^{27}$. Schmidt

\footnotetext{
${ }^{25}$ GUTENBERG. Manaus, ano I, n. 25, 1/7/1892.

26 TELES, Luciano Everton Costa. Entre perseguições, agressões e empastelamentos: o caso dos jornais de trabalhadores Gutenberg (1891-1892) e Operário (1892) no Amazonas na Primeira República Brasileira. Aedos, Porto Alegre, vol. 7, n. 17, p. 24, Dez. de 2015.

${ }^{27}$ MACIEL, Osvaldo Batista Acioly. Filhos do trabalho, apóstolos do socialismo: os tipógrafos e a construção de uma identidade de classe em Maceió (1895-1905). Dissertação (Mestrado em História), PPGH/UFP, Recife, 2004, p. 121
} 
explicitou que o socialismo de Xavier e Cavaco, importantes lideranças socialistas do Rio Grande do Sul, era eclético, incorporando elementos das correntes de pensamento vigentes na virada do século XIX para o século XX. Sobre o socialismo eclético salientou Pansardi:

Um socialismo que constrói seu aparato teórico e seu discurso com uma ampla gama de autores de diferentes origens teóricas e políticas, e que não tem como centro a teoria de nenhum autor em especial, um socialismo que não é marxista, proudhoniano, lassaleano, maloniano, ou outro qualquer onde muitas vezes temos dificuldades de separar as várias ideologias socialistas entre si. O socialismo eclético é, em realidade, aquele que domina entre os militantes socialistas do final do século, e mesmo entre os primeiros anos do século $\mathrm{XX}^{28}$.

No caso do Amazonas, as lideranças socialistas desse primeiro momento realizavam contatos com os militantes localizados em diversas regiões do país, por meio de correspondências e permutas de jornais que agilizavam a circulação de informações e ideias. Esses contatos eram registrados nos jornais, como se pode atestar no exemplo abaixo:

Recebemos os seguintes jornaes:

"O Purus", da Lábrea, no interior do Estado; o Humaithaense, de Humaytá, idem.

Do Pará, "Tribuna Operária", "O Democarta", "O Pimpão" e "Gazeta Postal". Do Maranhão: "O Artista Caxiense", "O Nacional" e o "Comércio de Caxias". Do Piauhi, "O Democrata".

Da Fortaleza: "Libertados", "O Norte", " O Operário", O Bemtivi", "Estado do Ceará", "A República", e o "Cruzeiro de Baturité".

Do Rio Grande do Norte: "O Povo", e "A República".

De Maceió: "Cruzeiro do Norte", "Gazeta de Alagoas" e "A Troça".

Da Bahia: "O Guarany" e "Pequeno Jornal".

De Campos: "Monitor Campista" e "Brazil Philatelico".

De São Paulo: "A Verdade" e "Luz" e, da Capital Federal: "L’Etoile do Sul" ${ }^{\prime 29}$.

Esses contatos geravam referências que influenciavam e/ou tentavam influenciar o movimento operário local. Nesse sentido, identificou-se o nome de José Augusto Vinhaes, expoente do partido operário do Rio de Janeiro e Deputado Federal ${ }^{30}$. Vinhaes foi sublinhado por acompanhar e apoiar os movimentos grevistas; por buscar mediar o conflito; e, uma vez não sendo realizado qualquer tipo de acordo, por procurar fortalecer o operariado em ralação à burguesia, tentando impedir a violência policial, ou seja, as forças de repressão ${ }^{31}$.

\footnotetext{
${ }^{28}$ PANSARDI, Marcos Vinícius. O socialismo dos modernos e o socialismo dos antigos: a incorporação do vocabulário ideológico da II Internacional pelo movimento socialista brasileiro. História Social. São Paulo, n. 1, p. $69,1994$.

${ }^{29}$ IMPRENSA. Gutenberg. Manaus, ano I, n. 19, 1/5/1892.

${ }^{30}$ GUTENBERG. Manaus, ano I, n. 19, 1/5/1892.

${ }^{31}$ PANSARDI, Marcos Vinícius. O movimento operário e a República. Estudos de Sociologia. Vol. 3, n. 5, p. 97, 2008.
}

CANOA DO TEMPO - Revista do Prog. Pós-Graduação em História, Manaus, V. 9 - no1, dez 2017. 
Mas não era somente o partido operário de Vinhaes e ele próprio que ganhavam as páginas dos jornais. Outras regiões e seus partidos operários, como o do Estado de Alagoas, eram explicitados e tomados como referências. Sobre o partido operário de Alagoas:

Da "Troça" de Maceió de 30 de Maio transcrevemos o seguinte:

"Hontem á tarde como estava annuhciado nos jornaes da capital, teve logar na casa de residência do cidadão artista Canuto Passos, a rua do Queimado, em Jaraguá, a organisação do Partido Operário Alagoano, comparecendo a installação cidadãos de diversas classes.

Por volta de 5 horas da tarde, o cidadão Daniel Custódio, a convite da commissão encarregada da Liga Operária, occupando a cadeira de Presidente da reunião, declarou aberta a sessão inaugural do partido, ordenando em seguida que o consocio Philomeno Coelho expuzesse aos circumstantes o programma das bases do partido, que foi muito enthusiasticamente acceito" ${ }^{32}$.

Atenta-se para o fato de que a menção sobre o surgimento de partidos operários em outras regiões do país se coloca basicamente como um convite aos trabalhadores amazonenses para efetuarem o mesmo, ou seja, criar o seu partido operário, o que foi feito, como se verá mais adiante no texto.

Portanto, constata-se o que Batalha chamou de "construção de paradigmas" ou "modelos"33 elaborados para servirem de exemplos a serem seguidos e, dessa forma, influenciar as organizações e ações dos operários no Amazonas, que jamais estiveram restritos ao extremo norte. O socialismo local estava vinculado a outras regiões e umbilicalmente amarrado na II Internacional.

Desse modo, a participação no processo político-eleitoral no interior da democracia representativa burguesa era aceito, assim como a já mencionada colaboração entre as classes e as reformas sociais por meio de legislações específicas aprovadas no parlamento. Não foi à toa que Vicente de Paula Galvão, tipógrafo, elaborou um artigo, que foi publicado no jornal Gutenberg, solicitando o comparecimento dos companheiros numa reunião que seria brevemente comunicada. Eis o conteúdo do texto:

Em quasi todas as capitaes do mundo têm-se operado o grande movimento artístico com os mais sublimes resultados.

A arte typographica, que, sendo como é, uma das mais importantes invenções da humanidade, deve collocar-se também na vanguarda das associações.

Em Manaós, que um typographo não é mais nem menos do que um simples artista, pode, entretanto, sahir desse marasmo, onde por tanto tempo se acha collocado.

\footnotetext{
32 PARTIDO OPERÁRIO. Gutenberg. Manaus, ano I, n. 25, 1/7/1892.

33 BATALHA, Claudio. Identidade da Classe operária no Brasil (1880-1920): Atipicidade ou legitimidade. Revista Brasileira de História, São Paulo: v. 12, n. 23/24, p. 111-124, set./ago.1992.
} 
Em São Paulo, por exemplo, que os typographos com mui diminuto numero, isto é inferior a nós aqui no Amazonas tem sabido elevar-se e elevar a classe a tal ponto de se fazer representar nos grandes movimentos populares.

Têm uma bôa associação, vivem todos bem colligados e assim têm chegado a rivalisar com muitas das melhores sociedades no sul da União.

Assim também, collegas do Amazonas, unamo-nos, que não estará talvez, muito longe o dia em que sahindo do obscurantismo em que vivemos, dizer ao mundo inteiro: - "Nós, os typographos, aqui no Amazonas somos grandes também; temos a nossa associação, vivemos uns para os outros e, assim unidos podemos apparecer no meio da grande e humanitaria sociedade amazonense"!

Faço, portanto, um apello nestas collumnas aos meus dedicados collegas, para comparecerem a uma reunião, que brevemente será comunicada.

No dia da reunião pede-se o comparecimento de todos ${ }^{34}$.

Não se deve deixar passar despercebida a referência que esse personagem faz aos tipógrafos de São Paulo que, certamente, existiam em quantidades maiores que os do Amazonas, porém, como se registrou anteriormente, isso fazia parte da "construção de modelos". O trecho da citação acima é importante porque pouco tempo depois foi criado o partido operário no Amazonas, o primeiro de outros que serão criados posteriormente.

Não obstante, em função da instabilidade inicial do regime republicano, especialmente com o fracasso do golpe realizado por Marechal Deodoro e, a partir daí, a ascensão de Floriano Peixoto à Presidência do Brasil, alterou-se o quadro local, uma vez que o governador do Amazonas, Thaumaturgo de Azevedo, era ligado à Fonseca e com a emergência de Peixoto foi deposto em favor de Eduardo Ribeiro. O jornal Operário apoiava Azevedo, desferindo críticas ferrenhas ${ }^{35}$ ao novo governador que não poupou esforços no sentido de perseguir, agredir e fechar o referido jornal e, talvez com ele, o nascente partido operário ${ }^{36}$.

\section{João Cursino da Gama: liderança socialista em ação}

Voltando ao personagem. Essas primeiras experiências socialistas foram importantes para Gama. Ele não partiu do nada e muito menos de uma intuição qualquer em termos de socialismo. Muito pelo contrário, certamente se serviu do pequeno acúmulo de luta do movimento operário amazonense que se refletiu nas associações criadas, nos partidos operários fundados, na literatura socialista (Marx, Engels, Malon, Branqui, etc.) que circulava nas bibliotecas das associações e nas colunas dos jornais operários.

\footnotetext{
${ }^{34}$ MOVIMENTO TYPOGRAPHICO. Gutenberg. Manaus, ano 1, n. 1, 15/11/1891.

35 Antes do seu desparecimento, nos dois primeiros números, o jornal Operário publicou alguns artigos que teciam críticas ao governo de Eduardo Ribeiro. Uma das críticas mais robusta se deu num artigo intitulado "Governo do Terror", de autoria de Santos Porto. Dividido em duas partes (portanto publicado nos dois números existentes da folha) este artigo apontava como elementos que compunham suas admoestações as perseguições, a censura e a corrupção. Ver PORTO, Santos. Governo do Terror I. Operário. Manaus, ano I, n. 1, 12/12/1892; PORTO, Santos. Governo do Terror II. Operário. Manaus, ano I, n. 2, 19/12/1892.

${ }^{36}$ TELES, Luciano Everton Costa. Entre perseguições, agressões e empastelamentos... Op. Cit., p. 34-37.
} 


\section{IMAGEM 1}

\section{João Cursino da Gama}

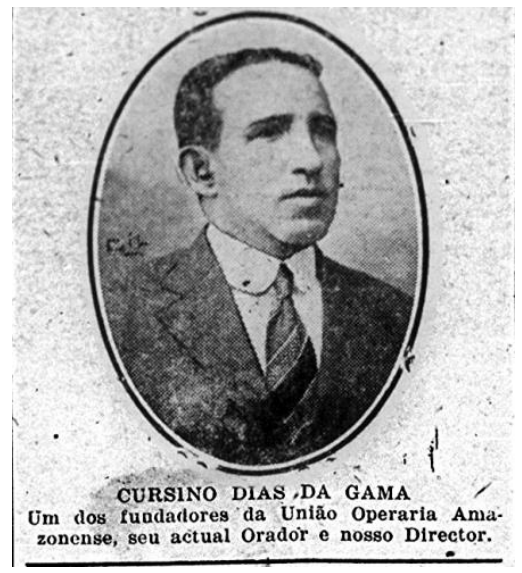

Fonte: O Primeiro de Maio (número especial). Manaus, 1/5/1928.

A atuação de João Cursino da Gama ficou registrada nas páginas da imprensa operária pelas suas ações de militância no Amazonas. Da mesma forma que outras lideranças socialistas, como Nicodemos Pacheco, Joaquim Azpilicueta e Manoel Sérvulo, e anarquistas, como Tércio Miranda, inseriu-se numa dinâmica de incentivo e orientação organizacional, com o objetivo de contribuir para a luta operária ${ }^{37}$. Sobre ele Pinheiro e Pinheiro destacaram que "na luta operária, acompanhou de perto as manifestações e greves de diversas categorias, como a dos estivadores, carroceiros ou dos motoristas de bondes da Manaós Tramways"38.

Gama movimentou-se entre diferentes grupos, que possuíam inclusive posições divergentes, conclamando a superarem suas diferenças e a construírem um consenso em torno de questões específicas como, por exemplo, as eleições governamentais ${ }^{39}$. Sobre isso ele sublinhava:

O indifeferentismo do operário as coisas políticas do nosso Estado é um erro irremissível (...) E qual o meio mais viável de cooperarmos nessa tão anciada salvação? Unificando-nos, e correndo as urnas por occasião de ferir-se o pleito governamental, afim de collocarmos um homem que reúna, todos os requisitos indispensáveis a um perfeito chefe de Estado (...) justo, intelligente, honrado... ${ }^{40}$

Tal artigo foi preparado para publicação um pouco antes das eleições estaduais ocorrerem, cenário este que fez com que Gama externasse aquilo que ele via como fundamental: eleger um "chefe de Estado" que, para além dos adjetivos frisados, atendessem as reivindicações dos trabalhadores - oito horas de trabalho, intermediação do Estado na

\footnotetext{
${ }^{37}$ GAMA, João Cursino da. A posto! O Extremo Norte. Manaus, ano I, n. 13, 8/4/1920.

38 PINHEIRO, Luís Balkar Sá Peixoto, PINHEIRO, Maria Luiza Ugarte. Mundos do trabalho na cidade da borracha: trabalhadores, lideranças, associações e greves operárias em Manaus (1880-1930). Jundiaí: Paco Editorial, 2017, p. 212.

${ }^{39}$ GAMA, João Cursino da. O momento. Vida Operária. Manaus, ano I, n. 9, 4/4/1920.

${ }^{40}$ GAMA, João Cursino da. A posto! O Extremo Norte. Manaus, ano I, n. 13, 8/4/1920.
} 
relação capital/trabalho, promoção da estabilidade no emprego, etc. Além disso, as posições de Gama eram pautadas "sempre pela moderação, assumindo, por vezes, uma posição dissidente e contrária a deflagração de greves, propondo em seu lugar a negociação com o patronato",41.

Mas não era somente isso que ele defendia. Ainda fazendo sobressair sobre seus escritos às eleições político-partidárias, apontou a criação e a consolidação de um partido operário no Amazonas como ponto fulcral da luta:

No próximo domingo, 7, às nove horas, terá logar, no Theatro Alcazar, gentilmente cedido pelo seu illustre proprietário dr. Raymundo Fontenelle, a primeira reunião operária para a fundação do Partido Operário Amazonense. Como medida de precaução, o nosso companheiro Cursino Gama, previne a todos os nossos companheiros de classe, que o futuro P. O. A. nenhuma ligação terá com as diversas aggremiações políticas, que se degladiam no Estado; bem assim que somente aos operários no goso de seus direitos civis e políticos, como cidadãos brazileiros, será permittido filiarem-se a esse Partido, de accordo com a Constituição Federal Brazileira, quer sejam ou não eleitores.

Todos os operários, trabalhadores, etc. devem comparecer a essa reunião, aonde serão apresentadas as bases para a organisação do mesmo.(...) Que seja coroado de bom êxito o primeiro passo dos nossos companheiros, em prol da emancipação operária local, são nossos votos ${ }^{42}$.

Consoante Gama, o P. O. A. tinha que ser composto somente por trabalhadores, para defender a causa operária. Essa linha de organização e ação era difundida através do jornal $O$ Extremo Norte, periódico onde Gama contribuía. Por esta folha operária é possível verificar uma forte conexão com outras regiões do Brasil, da América Latina e da Europa.

Um exemplo que permite demonstrar essa conexão está no próprio jornal. Consiste num artigo intitulado "O Extremo Norte em São Paulo e Iquitos”, no qual os responsáveis pela folha operária procuram traduzir em palavras a recepção que o periódico teve nessas localidades $^{43}$. Do mesmo modo, os artigos que versam sobre temas de outras regiões nacionais e internacionais -, e que ganharam as páginas d'O Extremo Norte ${ }^{44}$, reforçam a existência desses contatos.

Mas além da colaboração no jornal $O$ Extremo Norte, Gama não deixou de escrever no periódico Vida Operária. Aliás, envolveu-se mesmo na direção de uma folha operária

\footnotetext{
${ }^{41}$ PINHEIRO, Luís Balkar Sá Peixoto, PINHEIRO, Maria Luiza Ugarte. Mundos do trabalho na cidade da borracha... Op. Cit., p. 213.

${ }^{42}$ GAMA, João Cursino. A posto! O Extremo Norte. Manaus, ano I, n. 13, 8/4/1920.

${ }^{43}$ O EXTREMO NORTE EM SÃO PAULO E IQUITOS. O Extremo Norte. Manaus, ano I, n. 13, 8/4/1920.

${ }^{44}$ Como exemplo pode-se destacar o artigo denominado "O Syndicalismo na Inglaterra", que busca desenhar a trajetória desse sindicalismo, sem deixar de demarcar a sua situação atual. O SYNDICALISMO NA INGLATERRA. O Extremo Norte. Manaus, ano I, n. 13, 8/4/1920.
} 
específica, comemorativa do Primeiro do $\mathrm{Maio}^{45}$. Nela conseguiu reunir dirigentes de associações e lideranças importantes que aproveitaram o espaço e a data para falar da imprescindível ação organizativa do operariado para a construção de um mundo melhor, com justiça social.

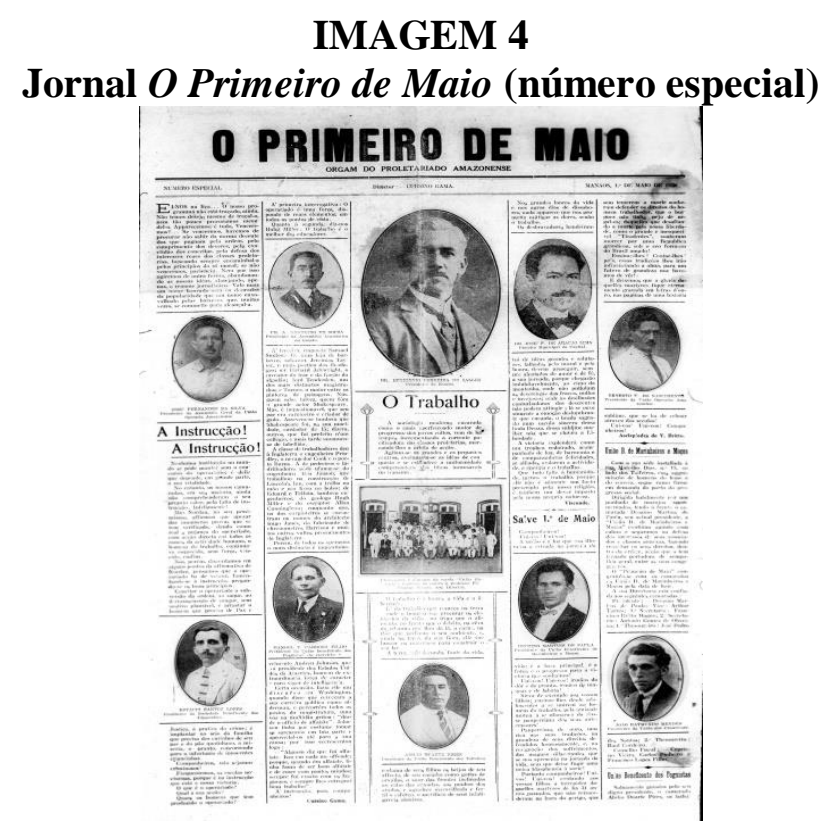

Fonte: reproduzido do microfilme a partir do acervo do Laboratório de História da Imprensa no Amazonas.

Por esse jornal já é possível verificar que algumas demandas sociais dos socialistas foram apropriadas no processo de elaboração, na década de 1930, do trabalhismo, especificamente no processo de formação ideológica deste último. Não se quer com isso correr riscos de anacronismos e muito menos se inserir numa discussão que continua polêmica e espinhosa. Porém, não é viável se esquivar dessa questão e muito menos deixar de contribuir apontando caminhos para um período que no Amazonas ainda carece de pesquisas históricas. Nessa direção, a trajetória de João Cursino da Gama é primordial, pois propicia adentrar em algumas questões elementares desse momento.

\section{João Cursino da Gama e a "Invenção do Trabalhismo" no Amazonas}

Como se pode reparar, Gama foi uma liderança operária marcante no cenário político regional da Primeira República e continuou sendo após a ascensão de Getúlio Vargas à Presidência do Brasil. Sabe-se que nesse processo ocorreram descontinuidades, porém não se podem desprezar as continuidades, e uma delas é a luta operária por melhores condições de vida e trabalho. Algumas trajetórias de militantes oportunizam confirmar essas permanências.

${ }^{45}$ O PRIMEIRO DE MAIO - Edição comemorativa (1928). 
Gama é uma delas, sobretudo porque ele está presente antes e depois de 1930, falando em nome dos trabalhadores.

Após a publicação do jornal O Primeiro de Maio, em 1928, não se tem mais notícias de Gama à frente de jornais operários, pode ser que tenha continuado (e os jornais desaparecidos dos arquivos locais). Mas ele apareceu nas colunas do Jornal do Commercio ao longo dos anos de 1930. Este jornal informava sobre as audiências públicas realizadas pelo governador do Estado e foi nesta seção que o nome dele voltou a surgir. Ele foi recebido pelo governador algumas vezes, como em fevereiro de $1928^{46}$.

No ano seguinte, o mesmo periódico revelou algo surpreendente - pois se constitui emcaso raro nesse quadro e, consequentemente, ainda não iluminado pela historiografia regional -, qual seja, a eleição de Gama para o Conselho Municipal nos anos finais da década de 1920. O fato de João Cursino da Gama ter sido eleito para o Conselho ensejou que ele pudesse "falar em nome da classe trabalhadora" 47 e até mesmo informar sobre a eleição e a posse da diretoria da União Operária Nacional/Seção Amazonas ${ }^{48}$.

E não para por aí! Ele adentra o início da década de 1930 como vereador da Câmara Municipal, com o apoio de amplos setores organizados dos operários. Isso é significativo, uma vez que se atentarmos para esse novo momento, Gama pode ser elucidativo, assim como outras lideranças que certamente seguem nessa mesma direção (e aqui faltam pesquisas), para se compreender a emergência da "invenção do trabalhismo" e suas particularidades locais.

Um primeiro aspecto a considerar é que desde o pré-30 Gama já sublinhava a necessidade de reformas sociais, da colaboração de classes e da arbitragem, sob a responsabilidade do Estado, dos conflitos decorrentes da relação entre patrões e empregados. Esse processo continua no pós-30, porém com o Estado buscando se apropriar dessa "fala operária" e, a partir dessa apropriação, instituir o "mito de outorga". Para utilizar as palavras de Paranhos, instituiu-se o "roubo da fala" com o objetivo de minimizar/eliminar os conflitos de classes e tentar apagar da memória dos trabalhadores as lutas travadas nas décadas anteriores $^{49}$, que inclusive resultaram em algumas leis direcionadas ao trabalho (antes de 1930), como a regulamentação do trabalho do menor e da mulher, a lei de férias e de acidente de trabalho ${ }^{50}$.

\footnotetext{
46 JORNAL DO COMMERCIO. Manaus, ano 25, n. 8316, 4/2/1928.

${ }^{47}$ A EDILIDADE. Jornal do Commercio. Manaus, ano 26, n. 8702, 15/5/1929.

48 JORNAL DO COMMERCIO. Manaus, ano 27, n. 9012, 9/5/1930.

${ }^{49}$ PARANHOS, Adalberto. O roubo da fala: origem da ideologia do trabalhismo no Brasil. São Paulo: Boitempo Editorial, 1999.

${ }^{50}$ Ver GOMES, Ângela de Castro. Cidadania e direitos do trabalho. Rio de Janeiro: Zahar, 2002.
} 
Como salientou Gomes, o trabalhismo é um discurso ideológico que além de se apropriar dessa "voz operária", assenta-se na formatação do sindicalismo corporativista e na legislação trabalhista e previdenciária utilizados como capital político por Vargas e os grupos que se alinhavam a ele ${ }^{51}$.

Gama, como foi visto anteriormente, principalmente ao ser responsável pela publicação do jornal $O$ Primeiro de Maio (1928), inclinou-se quase sempre para a colaboração de classes e a implantação de reformas sociais via parlamento. Essa perspectiva reformista o levou a apoiar nomes de candidatos não necessariamente operários, seja para cargos majoritários e/ou no parlamento. Portanto, aceitava o jogo político-eleitoral, daí seu envolvimento na fundação de um Partido Socialista Amazonense na década de 1920. Toda essa movimentação fez com que ele próprio se candidatasse a uma cadeira no parlamento municipal, vencendo as eleições.

Não obstante, provavelmente entrou em contato com duas lideranças "trabalhistas" que foram forjadas nesse momento de 1930, Luiz Tirelli e Álvaro Maia, e, dessa forma, deu sua contribuição ao processo de "invenção do trabalhismo no Amazonas". Aqui reside o segundo aspecto a observar: considerar os trabalhadores como atores históricos, os quais à frente de um repertório de possibilidades tiveram que operacionalizar escolhas.

Nesse sentido, retirar a condição de atores históricos de homens como João Cursino da Gama, negligenciando suas escolhas e considerando-o como uma "coisa" manipulada por líderes populistas e/ou encarando-o como um líder populista, é desconsiderar aspectos de sua trajetória sublinhados neste texto.

\section{CONSIDERAÇÕES FINAIS}

Como se pode notar, a trajetória de João Cursino da Gama proporciona a realização de discussões de temas mais gerais ligados a História do Trabalho local e nacional (e diria até internacional), como, por exemplo, a luta operária, o socialismo e até mesmo a "invenção do trabalhismo" no Amazonas. Dessa forma, os estudos de trajetórias são significativos não somente por recuperar lideranças operárias importantes que foram silenciadas pela historiografia, mas também porque permitem, a partir das "expressões individuais", a compreensão de aspectos mais gerais das relações de trabalho no Amazonas.

Sobre a questão da "invenção do trabalhismo" local, esses estudos viabilizam focar nas continuidades entre o pré e o pós-30, principalmente no que tange a luta operária e seus

\footnotetext{
${ }^{51}$ GOMES, Ângela de Castro. A invenção do Trabalhismo... Op. Cit.
} 
agentes, vistos como atores do processo histórico, corroborando com uma historiografia mais recente que busca reforçar esse aspecto. No Amazonas, sabe-se que esse período necessita de uma maior atenção. Cabe ampliar e aprofundar as pesquisas sobre o trabalhismo na região e os estudos de trajetórias se colocam como uma proposta em potencial para se conhecer melhor esse período. 